\title{
Effectiveness of exercise with a mobile application on pain of knee
}

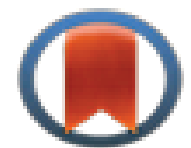 \\ osteoarthritis: a randomized clinical trial \\ CrossMark \\ Abbaszadeh Z1, Rashedi V², Amiri A3 ${ }^{3}$, Haghighi A ${ }^{4}$, ${ }^{2}$ Kianmehr $N^{5}$ \\ click for upelateo \\ 1- School of Medicine, Iran University of Medical Sciences, Tehran, Iran. \\ 2- School of Behavioral Sciences and Mental Health (Tehran Institute of Psychiatry), Iran University of Medical \\ Sciences, Tehran, Iran. \\ 3- School of Rehabilitation Sciences, Iran University of Medical Sciences, Tehran, Iran. \\ 4- School of Medicine, Iran University of Medical Sciences, Tehran, Iran. \\ 5- School of Medicine, Iran University of Medical Sciences, Tehran, Iran (Correspondent Author) \\ Email: kianmehr.n@iums.ac.ir
}

\begin{abstract}
Introduction: Knee osteoarthritis is the most common cause of pain in the older population and affecting about one third of the elderly throughout the world. There is some evidence that exercise could lead to pain improvement in elderly patients with knee osteoarthritis. Interventions that target physical activity in elderly patients are damaged by high dropouts. Low levels of compliance with exercise have become a major challenge for these patients. Using an educational app can be a solution to this challenge.
\end{abstract}

Method: the first step was to develop a sports application and an array of effective sports movements in the treatment of osteoarthritis was introduced to educate the patient. Then 135 patients with osteoarthritis with average age $60.6 \pm 6.18$ were randomly divided into two groups. Finally, 85 patients stayed in the intervention, of which $20(23 \%)$ were male. 57\% of the participants had Grade 2 knee osteoarthritis, 34\% Grade 3, and others with Grade 4. Patients were studied for 12 weeks. Exercise program was performed repetitively three times a day and pain variables (based on the WOMAC questionnaire) and (Lequesne questionnaire) at 0, 4, 12 weeks intervals.

Results: The average Pain score of patients after exercise was significantly decreased in both groups $(\mathrm{P}<0 / 05)$. Comparing the average Pain score of patients between the two application groups and the pamphlet, there was no significant difference in pain reduction, which indicates the effect of exercise on reducing pain regardless of the type of training and intervention.

Conclusion: The lower dropout percentage of patients that use the application $(25 \%)$ than pamphlets $(42 \%)$, indicates that the application can be used in future as an effective tool for patients education

Keywords: Elderly, Osteoarthritis, Mobile Application, Stretching Exercise, Strengthening Exercise

Received: 16 February 2019

Accepted: 12 March 2019

\begin{tabular}{|l|l|}
\hline \multicolumn{3}{|c|}{ Access this article online } \\
\hline & Website: \\
\hline www.joge.ir
\end{tabular}




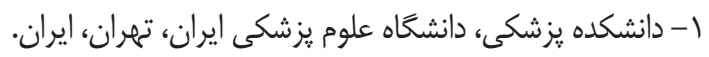

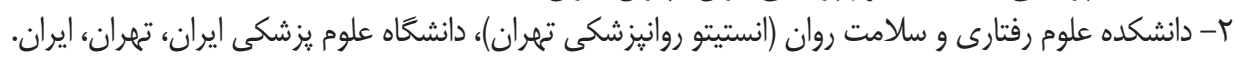

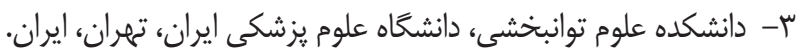

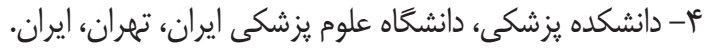

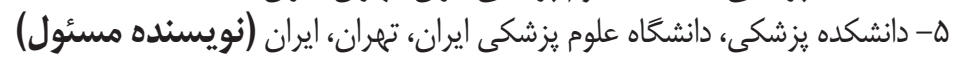

يست الكترونيكى: Kianmehr.n@iums.ac.ir

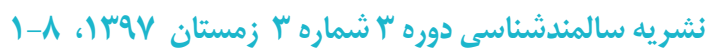

مقدمه: استئو آرتريت زانو مهمترين علت درد سالمندان در كل دنيا است كه يك سوم سالمندان را مبتلا مى كند. شواهدى وجود دارد

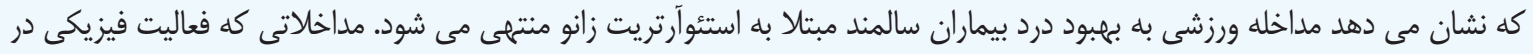

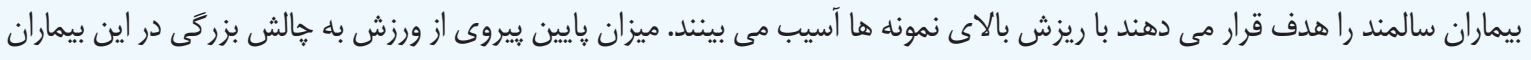

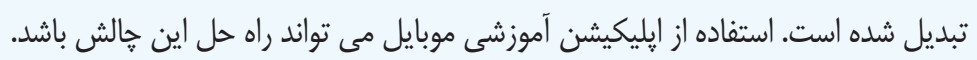

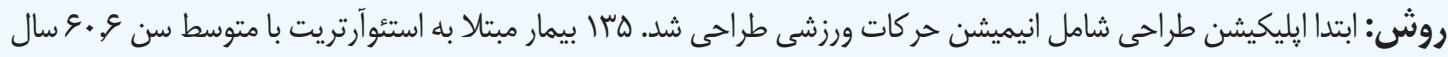

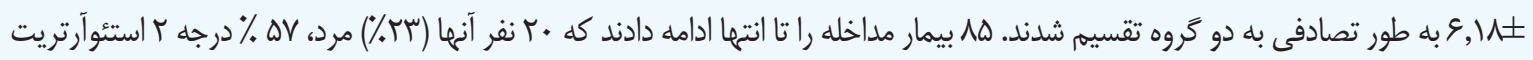

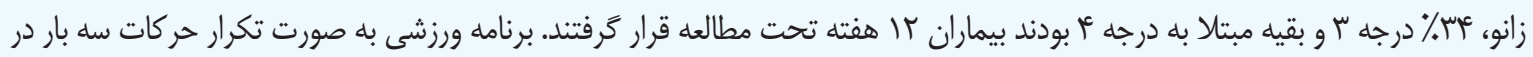

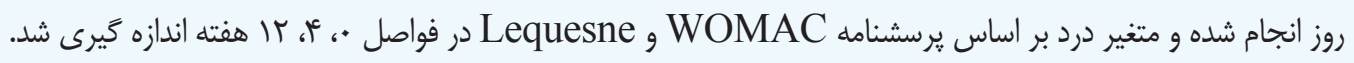

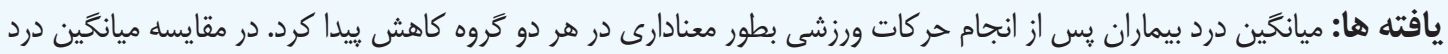

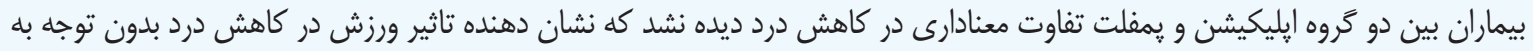
نوع آموزش و مداخله مى باشد.

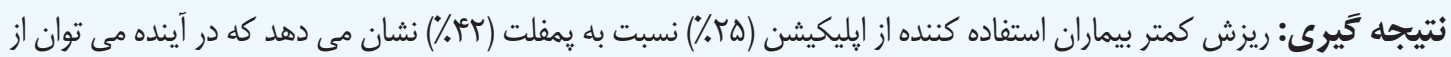

إيليكيشن جهت آموزش حر كات ورزشى به عنوان يك عنصر موثر در درمان بيماران مبتلا به استئوآرتريت زانو استفاده كرد.

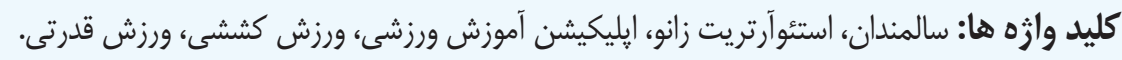


جهت مديريت درد تمركز يبيدا كرده است. يكى از اين رويكردها

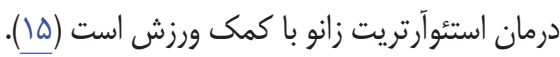
شواهدى وجود دارد كه نشان مى دهد مداخله ورزشى به بهبود درد و عملكرد بيماران سالمند مبتلا به استئوآرتريت زانو منتهى فهى مى شود.در مطالعه Baker و همكاران ورزش در منزل با شدت بالا باعث بهبود واضح در قدرت، درد، فانكشن فيزيكى و كيفيت زندگى

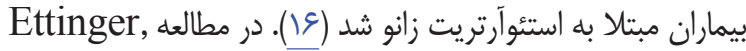

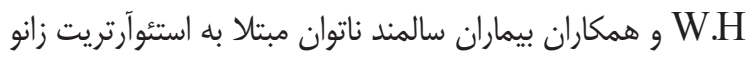

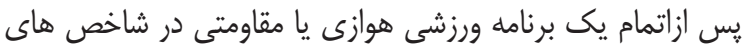

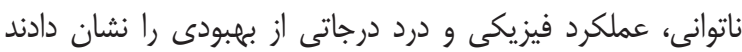
Petrella يك برنامه ييشرونده ورزشى علاوه بر داروهاى Non Steroidal Anti Inflammatory در برد بيماران مبتلا به استئوآرتريت زانو باعث بهبودى بيشترى در شاخص درد و فعاليت فيزيكى نسبت درمان دارويى به تنهايى مى شود (1)(1). در مطالعه Bennell ورزشهاى هوازى، آبى، تاى خاى (Tai chi) و تقويت كننده عضلات (Strengthening) براى بهبود درد و

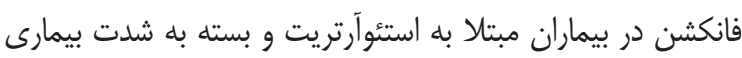

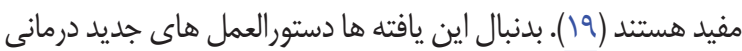

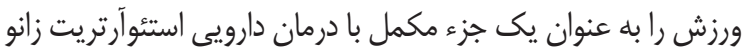

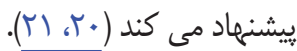
با توجه به اينكه مداخلاتى كه فعاليت فيزيكى در بيماران

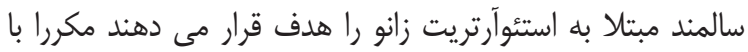

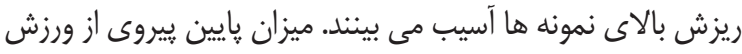

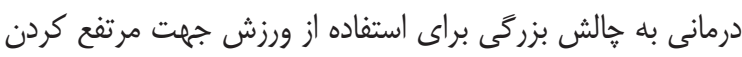

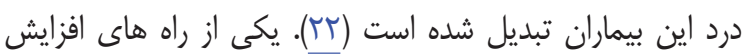

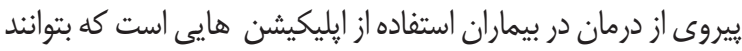

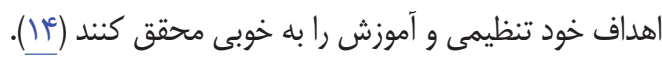
امروزه تلفن همراه به يكى از وسايل اصلى افراد تبديل شده اله

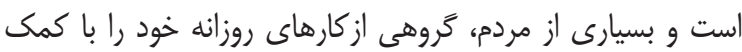
إيليكيشن هاى موجود براى اين وسيله انجام مى دهند. هدف اين

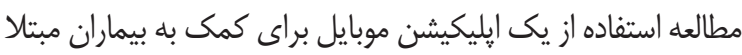

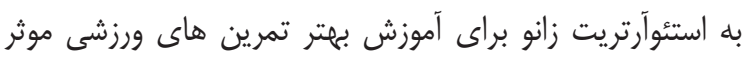

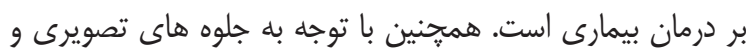

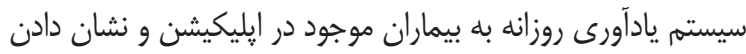
روند ييشرفت در انجام فعاليت هاى ورزشى، مقايسه اى بين آن با بان

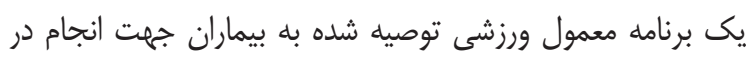

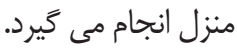

\section{مقاله}

در سال هاى اخير شاهد روند رو به رشد سالمندى در كل

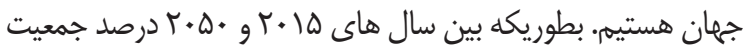

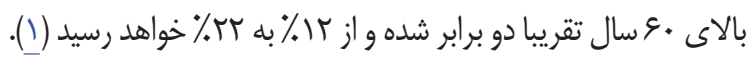

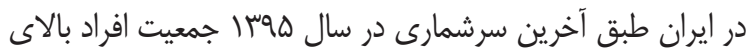

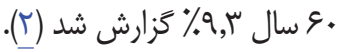

سالمندى با شيوع بيمارى هاى متعددى همراه است كه از جمله آنها مى توان به استئوآرتريت اشاره كرد كه دومين بيمارى

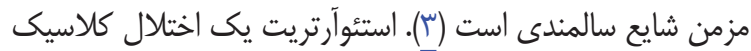
وابسته به سن است (أ) كه با تخريب غضروف مفصل شناخته (ب)

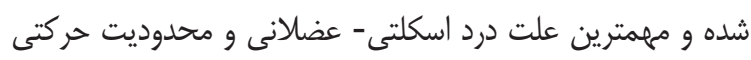

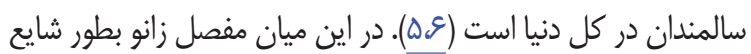
با استئوآرتريت درگير مى شود و اين درگيرى عمده ترين ناتوانى

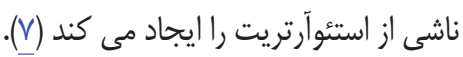

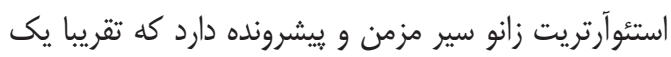

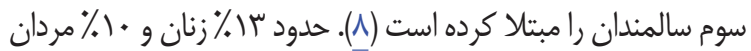
• ع سال و بالاتر مبتلا به انواع علامتدار استئوآرتريت هستند (9).

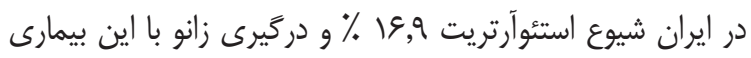

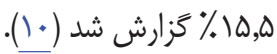

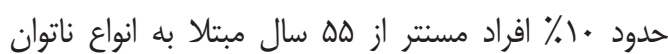

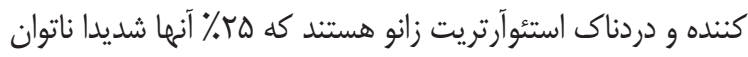
هستند. شيوع در استئوآرتريت زانو در مردان در مقايسه با زنان هان وايينتر است. زنان به به ويزه در بالاتر از سن هه سالكى به انواع شديدتر استئوآرتريت زانو سوق يبيدا مى كنند (9). در اغلب بيماران اولين تظاهرات بيمارى دردو محدوديت عملكرد جسمانى است (1). درد

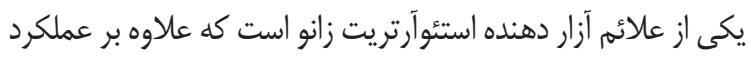

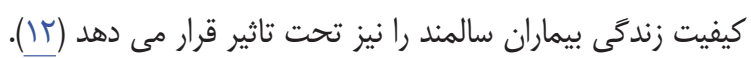

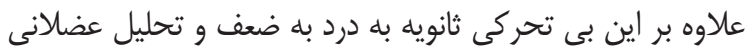

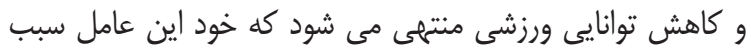
تشديد درد و تسريع ييشرفت ناتوانى عضلانى در بيمارات مبتلا بهان

استئو آرتريت مى شود (سا). مديريت موفق درد يك عامل اساسى براى حفظ سلامتى و به حداقل رساندن افت عملكردى بيماران سالمند مبتلا به استئوآرتريت

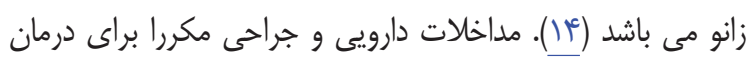

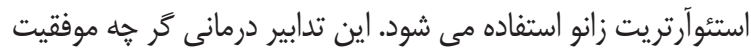
هايى ايجاد مى كند اما در طول زمان خود با عوارضى همراه مى شود. بنابراين در فقدان درمان قطعى براى استئوآرتريت زانو رويكردهاى إنى

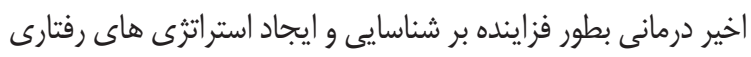




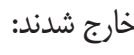

قرار نداشتن BMI در محدوده 1 • محدوديت در انجام ورزشهاى قدرتى (فشارخون كنترل نشده، بيمارى متابوليك كنترل نشده، اختلال كنترل نشده ضربانات بطنى ، نارسايى قلبى كتترل نشده، بيمارى دريجه اى شديد قلبى،

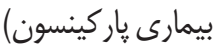

تزريق كورتون يا هيالكان داخل مفصلى و فيزيوترايى در طى شش ماه اخير

• داشتن شرح حالى از استئوآرتريت ثانويه (به دنبال تروما)

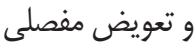

نداشتن تلفن همراه هوشمند يا غير اندرويدى

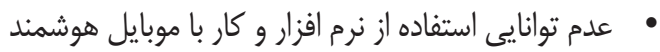

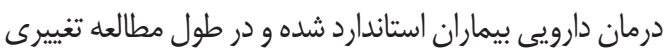

در آن ايجاد نشد. همه بيماران فرم رضايت نامه تاييد شده در كميته ديمان اخلاق را ير كرده اند.

سبك زندگى مناسب با بيمارى به همه بيماران آموزش داده

شده و بر اساس درجه دركيرى زانو حركات ورزشى مناسب به بيماران

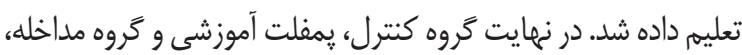
ايليكيشن ورزش در منزل را دريافت كردند. در هر دو گروه برنامه نهايى ورزشى در عرض ع هفته به صورت تدريجى از تعداد ورزش

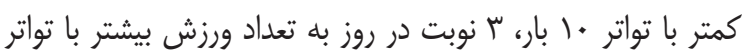

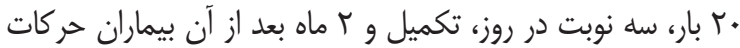
ورزشى متناسب با درجه درگيرى خود را با همين شدت ادامه دادند. گروه إيليكيشن قادر به رويت فيلم حر كات آموزشى، استفاده از زمان سنج حين اجراى حركات و سه نوبت يادآورى زمان بندى شده بر اساس ميل شخصى خود بر روى تلفن همراهشان بودند. در

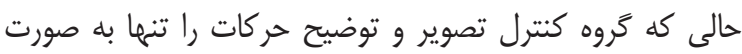
كتبى دريافت مى كردند. بيماران در شروع مطالعه هفته أ و هفته دوره rا با استفاده از نسخه فارسى يرسشنامه هاى داراى اعتبار و يايايى و و Wequesne تحت بررسى قرار گرفتند (rVAC يرسشنامه WOMAC شامل IV سوال است كه درجه مشكل براى انجام فعاليت هاى روزانه مثل استفاده از يله را جهت ارزيابى

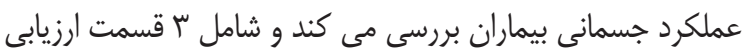
درد، سفتى مفصلى و عملكرد جسمانى مى باشد. از بيماران خواسته

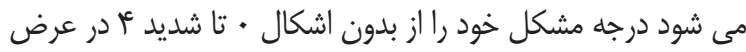

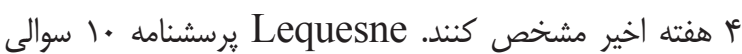
اختصاصى جهت بيماران مبتلا به استئوآرتريت زانو است. كه در آن درد حداكثر فاصله راه رفتن و فعاليت هاى روزانه بررسى مى شود.

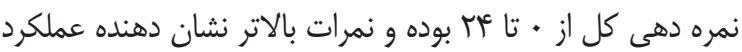

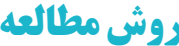

اين مطالعه يك كارآزمايى بالينى تصادفى شده با هس" بيمار هQ ساله و مسن تر مبتلا به استئوآرتريت زانو مراجعه كننده

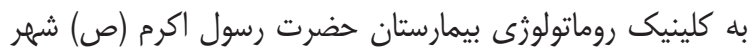

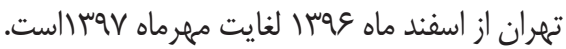

روش محاسبه حجم نمونه، تعداد آن

براساس مطالعه Deyle و همكاران ميزان بهبودى بر اساس

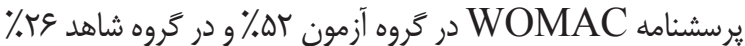

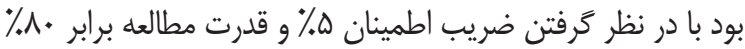
حجم نمونه لازم براى هر گروه •ه نفر مشخص شد.

$\mathrm{P}_{\perp=\cdot . \Delta Y}$

$\mathrm{Pr}=\cdot . r q$

$P)-p r=+r \varepsilon \quad n=[(Z \alpha / r+Z \beta) r \times\{(p)(1-p))+(p r$ $(1-\mathrm{pr}))\}](\mathrm{p} \iota-\mathrm{pr}) r$

$Z \alpha / r=1.99$

جهت اجراى مطالعه در ابتدا نياز به طراحى إيليكيشن

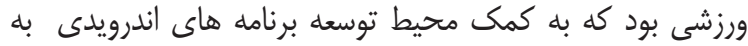
طراحى آن اقدام شد. در ايليكيشن مجموعه اى از حركات ورزشى

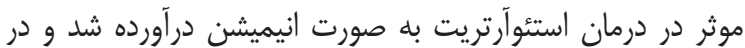
كنار هر حركت ورزشى توضيحات لازم نوشته شد. علاوه بر اينكه إيليكيشن قابليت پخش صوتى نحوه انجام حركت را دارد از قابليت هاى ديخرى همجون يادآورى زمان اجراى نوبت حركات، قابليت نمايش تعداد و زمان انجام هر حركت و استراحت بين حركات رات رات نيز دارا مى باشد. انتخاب حركات ورزشى طبق داده هاى مطالعات قبلى توسط متخصص فيزيوتر إييست انجام شد. در اين مطالعات موثر بودن ورزش هاى غيرايروبيك اندام تحتانى و تقويت كننده و كششى لشي عضلات اطراف مفصل زانو، در كاهش درد بيماران استئوآرتريت زانو

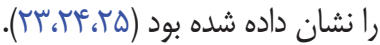
در مرحله بعد اقدام به جمع آورى نمونه شد و متخصص بود روماتولوزى بيماران شركت كننده در مطالعه را پس از از اعمال معيارهاى ورود و خروج ارجاع داده و بيماران به صورت تصادفى بر اساس شماره يرونده به دو گروه تقسيم شدند: (1) گروه ورزش در

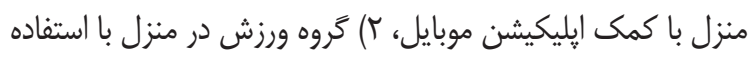

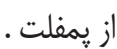
بيماران مبتلا به استئوآرتريت اوليه زانو كه در طبقه بندى كلغران و لورنس (عَ) درجه دو تا هِهار درگيرى را داشته باشند و بر اساس مقياس ACR مبتلا به استئوآرتريت شناخته شدند، وارد

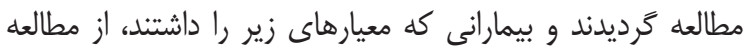


به منظور تجزيه و تحليل داده ها از نرم افزار SPSS و آزمون

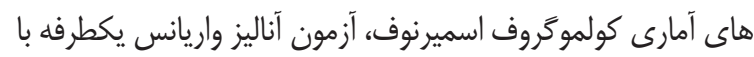
اندازه گيرى مكرر و تى مستقل استفاده شد.

\section{كافْته هن}

از بين هسا شركت كننده در نهايت هی بيمار مداخله را تا انتها

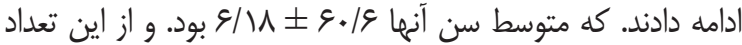

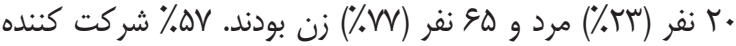

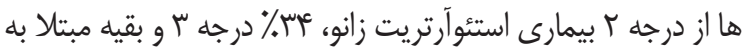

$$
\text { درجه أ بودند. }
$$

مطابق (جدول) مقايسه ميانگين نمرات درد يرسشنامه

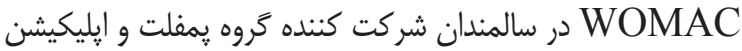
ورزشى نشان دهنده كاهش معنادار ه+|• P درد در هفته هاى أو rا نسبت به شروع برنامه ورزشى مى باشد.

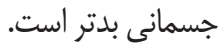

خلاصه جمع آورى نمونه ها و تكميل مطالعه در (نمودار ()

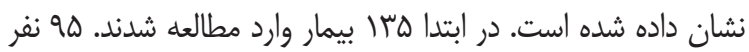
وارد گروه كنترل و • ع نفر وارد گروه إيليكيشن ورزشى شدند. در

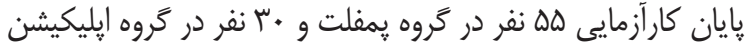
ورزشى باقى ماندند.

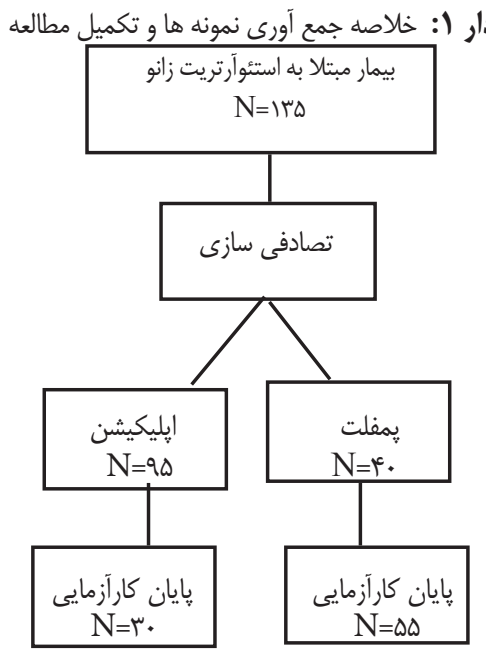

جدول (: مقايسه ميانكين نمرات درد يرسشنامه WOMAC در سالمندان شركت كننده گروه يمفلت و إيليكيشن

\begin{tabular}{|c|c|c|c|c|c|c|c|c|c|c|c|c|}
\hline \multicolumn{13}{|c|}{$\mathrm{N}=\Delta \Delta$} \\
\hline \multirow{2}{*}{$\mathrm{Pv}$} & \multirow[b]{2}{*}{$\mathrm{F}$} & \multirow{2}{*}{ MS } & \multirow{2}{*}{ df } & \multirow{2}{*}{$\mathrm{SS}$} & \multicolumn{2}{|c|}{ | (1 هفته } & \multicolumn{2}{|c|}{ F مفته } & \multicolumn{2}{|c|}{ شروع } & \multirow{2}{*}{\multicolumn{2}{|c|}{ متغير }} \\
\hline & & & & & استاندارد & ميانكين & استاندارد & ميانگَين & استاندارد & ميانخين & & \\
\hline $\begin{array}{l}<.1 \cdot \cdot 1 \\
<.1 \cdot \cdot 1\end{array}$ & $r \Delta / g$. & $\begin{array}{l}44 / 199 \\
4 \% / 99\end{array}$ & $1 / \Delta F$ & 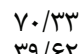 & - 109 & G/D. & $\cdot / \Delta \Lambda$ & $9|9|$ & .194 & $\begin{array}{l}V / q 4 \\
c \mid c c\end{array}$ & رِّمفلت & Pain \\
\hline$<\cdot / \cdots)$ & $10 / I V$ & $r r / 91$ & $1 / N r$ & rq/gr &.$|9|$ & W/ & . 199 & ץ/q4 &.$/ 8 \Lambda$ & $\varepsilon / 4 \varepsilon$ & إيليكيشن & \\
\hline
\end{tabular}

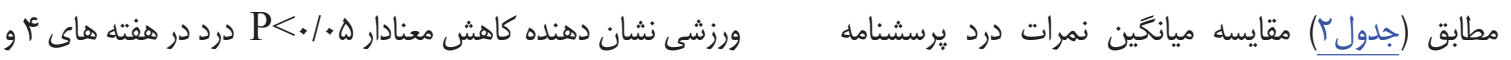

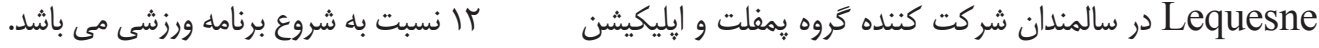
جدول r: مقايسه ميانگين نمرات درد يرسشنامه Lequesne در سالمندان شركت كننده گروه يمفلت و إيليكيشن

\begin{tabular}{|c|c|c|c|c|c|c|c|c|c|c|c|c|}
\hline \multicolumn{13}{|c|}{$\mathrm{N}=\Delta \Delta$} \\
\hline \multirow[b]{2}{*}{$\mathrm{Pv}$} & \multirow[b]{2}{*}{$\mathrm{F}$} & \multirow[b]{2}{*}{ MS } & \multirow[b]{2}{*}{$\mathrm{df}$} & \multirow[b]{2}{*}{ SS } & \multicolumn{2}{|c|}{ |r| هفته } & \multicolumn{2}{|c|}{ F هفته } & \multicolumn{2}{|c|}{ شروع } & \multirow{2}{*}{\multicolumn{2}{|c|}{ متغير }} \\
\hline & & & & & استاندارد & ميانگين & استاندافر & ميانكين & استاندارد & ميانگين & & \\
\hline$<\cdot|\cdot|$ & $r \varepsilon / q$. & $|8| .9$ & $1 / \wedge \Delta$ & rq/qr &.$/ T \Lambda$ & $r / v r$ & ع & س ب/א & rr/. & $\varphi / \Delta \Lambda$ & بِمفلت & Pain \\
\hline$<\cdot / \cdot+1$ & $r T / F I$ & $\mid g / T \Lambda$ & $1 / V \Lambda$ & $r q / .9$ & عس/. & $r / r$. &.$/ \mu \Delta$ & $r / .9$ &.$/ 4$. & سז/ץ & إيلّيكيشن & \\
\hline
\end{tabular}

كننده هر دو ₹روه نشان دهنده كاهش معنادارى بين گروه يمفلت و إِيكيشن ورزشى نبود.
مطابق (جدولَ) مقايسه ميانخين نمرات درد يرسشنامه و و يرسشنامه LOMAC جدول س: مقايسه ميانكَين نمرات درد يرسشنامه Lequesne و WOMAC سالمندان در گروه هاى مورد مطالعه (يمفلت/إيليكيشن ورزشى)

\begin{tabular}{|c|c|c|c|c|c|c|c|}
\hline \multicolumn{8}{|c|}{$\mathrm{N}=\wedge \bowtie$} \\
\hline \multicolumn{3}{|c|}{ ז| هفته } & \multicolumn{3}{|c|}{ F هفته } & \multirow{2}{*}{\multicolumn{2}{|c|}{ متغير }} \\
\hline $\mathrm{Pv}$ & $\mathrm{df}$ & $\mathrm{t}$ & $\mathrm{Pv}$ & $\mathrm{df}$ & $\mathrm{t}$ & & \\
\hline $\begin{array}{l}\text {. /NQV } \\
. / T \& 9\end{array}$ & $\begin{array}{l}\lambda \mu \\
\Lambda \mu\end{array}$ & $\begin{array}{l}1 / 44 . \\
1 / 119\end{array}$ & $\begin{array}{l}\cdot / \cdot V{ }^{2} \\
\cdot / r \cdot{ }^{2}\end{array}$ & $\begin{array}{l}\text { r } \\
\text { r }\end{array}$ & $\begin{array}{l}1 / \Lambda \cdot \Lambda \\
1 / T \Lambda 1\end{array}$ & $\begin{array}{l}\text { WOMAC يرسشنامه Lequesne } \\
\text { يرسشنامه }\end{array}$ & Pain \\
\hline
\end{tabular}


كروه سنى سالمند كه توانايى انجام ورزش شديد را ندارند اين شاخص كاهش يافته بود كه نشان مى دهد اضافه كردن به فعاليت فيزيكى سالمندان حتى در مقادير كم هم مى تواند باعث ايجاد تاثيرات مثبت

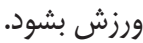

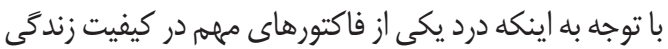
و عملكرد بيماران است بسيارى از درمان هاى دارويى جهت كاهش بانس

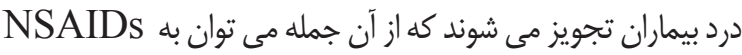

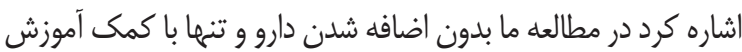
ورزش درد بيماران كاهش يافت كه با مطالعه Bartha و Petrella م مقايسه و درد بيماران را با يرسشنامه WOMAC و مى كرد مشابه بود (1) ). و نشان مى دهد ورزش با كمك مكانيسم هايى از جمله برداشتن بار وارده بر استخوان و غضروف با تقويت عضلات اطراف مفصلى در كاهش درد موثر است. يكى از مشكلات اساسى در مورد درمان مبتنى بر فعاليت

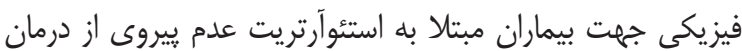
است علاوه بر اين آشنا نبودن يزشكان با نوع ورزش هاى موثر باعث مى شود كه توصيه به انجام ورزش توسط آنها كمتر انجام شده و

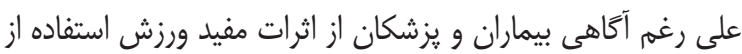
آن كاهش ييدا كند. با توجه به ريزش كمتر بيماران در كروه إيليكيشن به نظر مى رسد استفاده از اين نوع تكنولوزى عالاوه بر شامل بودن برن

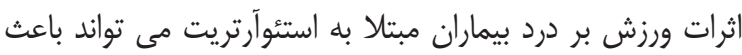
افزايش تبعيت بيماران از درمان ورزشى شود. على رغم اينكه در

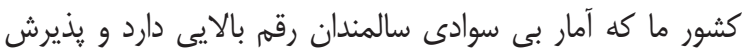
استفاده از إيليكيشن توسط سالمند سخت مى باشد اما قابليت يخش صوتى دستورالعمل هر حركت علاوه بر جلوه هاى تصويرى كمى الئى زيادى به آموزش بيماران سالمند مى كند. احتمال مى رود سادىى دادى استفاده از إيليكيشن و دركير بودن يزشك در نحوه درجه بندى شدات درگيرى بيماران و اطمينان از اينكه اين ورزش ها مثل هر درمان

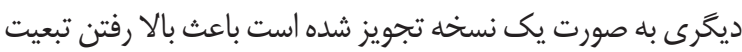

بيماران شود (9). (1).

طبق مطالعه ما بيماران گَروه مداخله (إيليكيشن) كاهش درد

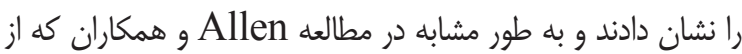

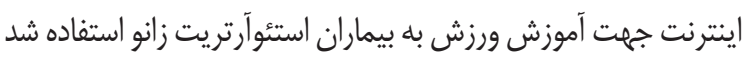
نمرات درد طبق يرسشنامه WOMAC در اين بيماران كاهش يافته بود. با اين تفاوت كه إيليكيشن ما نياز به اتصال به شبكه

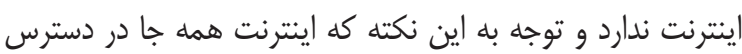

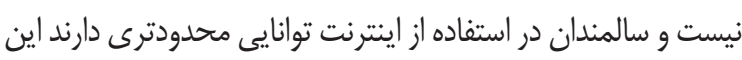

\section{بحث}

مطالعه حاضر نشان مى دهد ميانكَين درد بيماران مبتلا به استئوآرتريت زانو پِّ از انجام حركات ورزشى در هر دو كروه كنترل

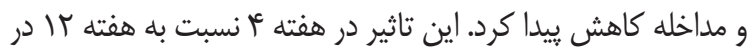
هر دو گروه بالاتر بود اما در نهايت ميانگين درد بيماران در هر دو دئ ارزيابى نسبت به سطح يايه بهبود يِيدا كرده بود. در مقايسه ميانكين

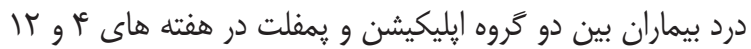

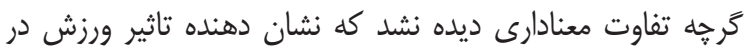

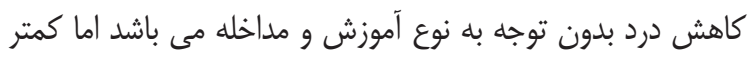
بودن نمرات ميانكين درد در كروه إيليكيشن نشاندهنده موثرتر بودن إنا

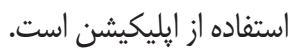
در مطالعه حاضر ورزش تجويز شده شامل تركيبى از حركات كششى و تقويت كننده عضله أ سر و كاف بود كه در نهايت باعث بهبود درد بيماران مى شدو با مطالعه Rogind و همكاران (1991)

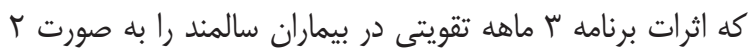
روز در هفته انجام حركات در مركز ورزشى و بقيه روزها تشويق به تكرار حركات در منزل مى شد كاهش واضح درد شبانه بيماران

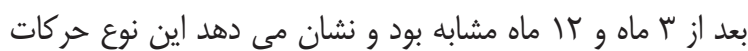
با تقويت عضلات اطراف مفصل و افزايش محدوده حركت مفصل باعث كاهش درد بيماران مى شوند (ب)ر.

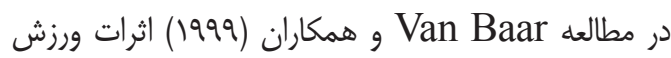
در مركز ورزشى در بيماران مبتلا به استئوآرتريت زانو و لكَن بررسى كرديد. طبق نتايج اين مطالعه ورزش هاى تقويتى باعث كاهش

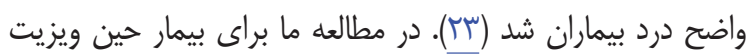
هاى روتين توسط يزشك ورزش شروع مى شد و نيازى به مراجعات مكرر به مراكز درمانى كه خود يكى از عوامل كاهش تبعيت تونيت از درمان است مرتفع مى شدو همين تاثير را بر بيمار داشت.

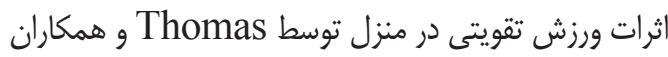

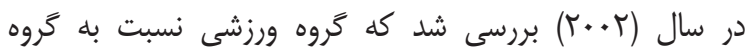

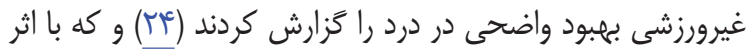
مطالعه ما هم خوانى داشت كه نشان مى دهد اينكه استفاده از بتواند

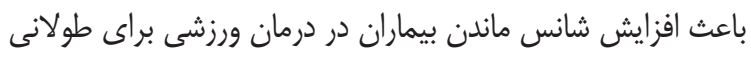
مدت بشود تا با كمك آن بتوان بر كوتاه بودن تاثيرات مثبت دران دران دران ورزش (ها) فائق آمد را مى توان با يبيخيرى طولانى تر بيماران در برد

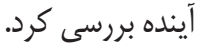

در مطالعه Baker و همكاران ورزش در منزل با شدت بالا باعث بهبود واضح در قدرت، درد، فانكشن فيزيكى و كيفيت زندگى بيماران مبتلا به استئوآرتريت زانو شد (عا) در مطالعه ما با توجه با فيا 


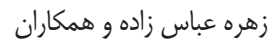

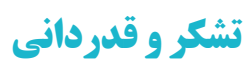

$$
\begin{aligned}
& \text { اين مقاله حاصل بخشى از يايان نامه مقطع دستيارى طب } \\
& \text { IR.IUMS.FMD.REC سالمندى مى باشد كه با كد اخلاق }
\end{aligned}
$$

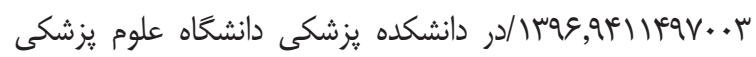

$$
\begin{aligned}
& \text { ايران به ثبت رسيده است. از كليه سالمندانى كه در انجام مطالعه } \\
& \text { نهايت همكارى را داشتند، تقدير و تشكر به عمل مى آيد. }
\end{aligned}
$$

\section{References}

1. Federal Interagency Forum on Agingrelated Statistics. Older Americans 2016: Key Indicators of Well-Being. (2016). Available from: https://agingstats.gov/docs/ LatestReport/Older-Americans-2016-KeyIndicators-of-WellBeing.pdf.

2. Nasiri N,et al. (2017), Socio-economic features of population aging in Iran (19572017). Iranian Statistical Research and Training Center.

3. United Nations, Department of Economic and Social Affairs, Population Division. World Population Ageing 2015. (2015). Available from: http://www.un.org/en/ development/desa/population/publications/ pdf/ageing/WPA2015_Report.pdf.

4. Williams WV, Cope R, Gaunt WD, et al. Metacarpophalangeal arthropathy associated with manual labor (Missouri metacarpal syndrome). Clinical radiographic, and pathologic characteristics of an unusual degeneration process. Arthritis Rheum 1987; 30:1362.

5. Peat G, McCarney R. Knee pain and osteoarthritis in older adults: a review of community burden and current use of primary health care. Ann Rheum Dis 2001; 60 (2): 91-7.

6. Thomas E, Peat G, Harris L, Wilkie R, Croft PR. The prevalence of pain and pain interference in a general population of older adults: crosssectional fi ndings from the North Staffordshire Osteoarthritis Project(NorStOP). Pain 2004; 110 (1-2): 361-8.

7. Felson D. T, Naimark A, Anderson J, Kazis L, Castelli W, and Meenan R. F, The

$$
\text { ويثزَى يكى ازمحاسن إيليكيشن به حساب مى آيد (•). }
$$

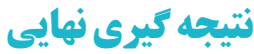

$$
\begin{aligned}
& \text { توجه به ريزش كمتر بيماران استفاده كننده از إيليكيشن }
\end{aligned}
$$

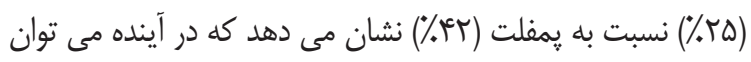

$$
\begin{aligned}
& \text { از إيليكيشن به عنوان يك ابزار موثر جهت آموزش و تشويق بيماران } \\
& \text { به انجام ورزش و فعاليت فيزيكى به عنوان يك جز اساسى در درمان } \\
& \text { بيماران مبتلا به استئوآرتريت زانو استفاده كرد. }
\end{aligned}
$$

prevalence of knee osteoarthritis in the elderly. The Framingham Osteoarthritis Study, Arthritis and Rheumatism, 1987; 30 (8): 914-918.

8. Eberhardt MS, Ingram DD, Makuc DM, et al. Urban and Rural Health Chartbook. Health, United States, 2001. Hyattsville, Maryland: National Center for Health Statistics. 2001.

9. Heidari B, Knee osteoarthritis prevalence, risk factors, pathogenesis and features: Part I, Caspian J Intern Med. 2011 Spring; 2 (2): 205-212.

10. Fereydoun D, Mahnaz S, et al, (2015). Epidemiology of rheumatic diseases in Iran from analysis of four COPCORD studies, International Journal of Rheumatic Diseases.

11. Osteoarthritis: national clinical guideline for care and management in adults. In: Conditions. NCCfC (Ed), Royal College of Physicians, London 2008.

12. Felson, D.T., Lawrence, R.C., Hochberg, M.C., McAlindon, T., Dieppe, P.A., Minor, M.A., et al. (2000). Osteoarthritis: New insights. Part 2: Treatment approaches. Annals of Internal Medicine, 133, 726-737.

13. Dekker, J., Boot, B., VanDerWoulde, L.H.V., \& Bijlsma, J.W.J. (1991). Pain and disability in osteoarthritis: A review of biobehavioral mechanisms. Journal of Behavioral Medicine, 15, 189-214.

14. Centers for Disease Control and Prevention, National Center for Health Statistics National Health Interview Survey, sample adult questionnaire: trends in health and aging. [Accessed July 10, 2008]. Available at: http://www.cdc.gov/nchs/agingact.htm.

15. Brian C. Focht, (2006). Effectiveness of Exercise Interventions in Reducing Pain 
Symptoms Among OlderAdults With Knee Osteoarthritis: A Review. Journal of Aging and Physical Activity, 14, 212- 235.

16. Baker, K.R., Nelson, M.E., Felson, D.T., Layne, J.E., Sarno, R., \& Roubenoff, R. (2001). The effi cacy of home based progressive strength training in older adults with knee osteoarthritis: A randomized controlled trial. Journal of Rheumatology, $18,1655-1665$.

17. Ettinger, W.H., Burns, R., Messier, S.P., Applegate, W., Rejeski, W.J., Morgan, T., et al. (1997). A randomized clinical trial comparing aerobic exercise and resistance exercise with a health education program in older adults with knee osteoarthritis. Journal of the American Medical Association, 277, 25-31.

18. Petrella, R.J., \& Bartha, C. (2000). Homebased exercise therapy for older patients with knee osteoarthritis: A randomized clinical trial. Journal of Rheumatology, 27, 2215-2221.

19. Bennell KL, Hinman RS. A review of the clinical evidence for exercise in osteoarthritis of the hip and knee. J Sports Sci Med 2011; 14 (1):4-9.

20. Minor, M., Stenstrom, C.H., Klepper, S.E., Hurley, M., \& Ettinger, W.H. (2003). Work group recommendations: 2002 exercise and physical activity conference. Arthritis Care and Research, 49, 453 - 454.

21. Minor, M. (2004). Impact of exercise on osteoarthritis outcomes. Journal of Rheumatology, 31, 81-85.

22. Brawley, L.R., Rejeski, W.J., \& King, A. (2003). Promoting physical activity for older adults:The challenges for changing behavior. American Journal of Preventive Medicine, 25, S172-S183.

23. VanBaar, M.E., Dekker, J., Oostendorp, R.A., Bijl, D., Voorn, T.B., \& Bijlsma, J.W. (2001). Effectiveness of exercise in patients with osteoarthritis of the hip or knee: Nine months' follow-up. Annals of Rheumatic Disease, 60, 1123-1130.

24. Thomas, K.S., Muir, K.R., Doherty, M., Jones, A.C., O'Reilly, S.C., \& Bassey, E.J. (2002). Home based exercise programme for knee pain and knee osteoarthritis: A randomised controlled trial. British Medical Journal, 325, 752 - 757.

25. Nejati P, Farzinmehr A, Moradi-Lakeh $M$. The effect of exercise therapy on knee osteoarthritis: a randomized clinical trial, Med J Islam Repub Iran, 2015 Feb; 29:186.

26. Kellgren JH, Lawrence JS, Bier F. Genetic factors in generalized osteoarthritis. Ann Rheum Dis 1963; 22:237.

27. Haidar N., Nasrin M., et al. (2012), Validity and reliability of the Persian versions of WOMAC Osteoarthritis Index and Lequesne Algofunctional Index, Clinical Rheumatology.

28. Rogind, M., Biblow-Nielsen, B., Jensen, B., Moller, H.C., Frimodt-Moller, B., \& Bliddal, H. (1998). The effect of a physical training program on patients with osteoarthritis of the knees. Archives of Physical Medicine and Rehabilitation, 79, 1421 - 1427.

29. Danbjørg D.B, et al. (2018), Usage of an Exercise App in the Care for People With Osteoarthritis: User-Driven Exploratory Study. JMIR Mhealth Uhealth. 2018 Jan; 6 (1): e11.

30. Allen K.D, et al.(2018), Physical therapy vs internet-based exercise training for patients with knee osteoarthritis: results of a randomized controlled trial. Osteoarthritis Cartilage. 2018 March ; 26 (3): 383-396. 